\title{
Indigenous Knowledge and Techniques of Runoff Harvesting (Bandsar and Khooshab) in Arid and Semi Arid Regions of Iran
}

\author{
Ali Akbar Nazari Samani ${ }^{*}$, Shahram Khalighi', Mahmood Arabkhedri², Jalil Farzadmehr ${ }^{3}$ \\ ${ }^{1}$ Faculty of Natural Resources, University of Tehran, Tehran, Iran \\ ${ }^{2}$ Soil Conservation and Watershed Management Research Institute, Tehran, Iran \\ ${ }^{3}$ Range and Watershed Management Department, University of Torbat-e-Heydarieh, Torbat-e-Heydarieh, Iran \\ Email: ${ }^{*}$ aknazari@ut.ac.ir
}

Received 19 April 2014; revised 16 May 2014; accepted 11 June 2014

Copyright (C) 2014 by authors and Scientific Research Publishing Inc.

This work is licensed under the Creative Commons Attribution International License (CC BY). http://creativecommons.org/licenses/by/4.0/

(c) (i) Open Access

\section{Abstract}

Two-thirds of Iran's landmass is considered a desert-land devoid of forests and green pastures. Such a harsh environmental condition ancient Iranian innovated amazing techniques and knowledge for supplying water, which are recently called indigenous knowledge. Rain water and runoff harvesting techniques are often applied to increase the water recharge and consequently productivity in arid regions. The sizes of runoff harvesting structures are varying form micro to macro landscape. Qanat, Khooshab, Bandsar and Degar are the most famous indigenous techniques of water resources management in Iran. We tried to introduce two methods (Bandsar and Khooshab), their classification and structure as well as benefits. Bandsar is a kind of flood farming structure ground water recharge prevailed in Khorasan province of eastern Iran. Depending on rainfall, land topography and geomorphology of area, different types have been established to use floods and agricultural activities. Their area is about 0.5 to 5 ha in alluvial fans and piedmont plain. Its structure consists of plots, basin and levee along contour lines and dry rivers. The upland generated runoff is stored in the basin to infiltrate. Moreover, the fine trapped sediment in Bandsar as a fertile material cause to improve sandy soils. Khooshab is another traditional method used in southeast of Iran (Sistan va Baluchistan). It is a wall structures built across or along the dry river to catch the summer Monson floods water and cultivation as well as combat to wind erosion. Their areas are about 1 - 10 ha and crops such as wheat, maize and barely are produced through them. Flood plains and piedmont are the best location for Khooshabs which caused aquifer recharging. This work tries to explain about environmental condition affect the outcomes of mentioned techniques and their side effects on decreasing soil erosion, flooding and desertification as well as productivity increasing in some parts of Iran. Our findings revealed that the efficiency of traditional knowledge is closely integrated with environment conditions and socio-economic situation

${ }^{*}$ Corresponding author.

How to cite this paper: Nazari Samani, A.A., Khalighi, S., Arabkhedri, M. and Farzadmehr, J. (2014) Indigenous Knowledge and Techniques of Runoff Harvesting (Bandsar and Khooshab) in Arid and Semi Arid Regions of Iran. Journal of Water Resource and Protection, 6, 784-792. http://dx.doi.org/10.4236/jwarp.2014.68074 
of rural community such as participatory. However, they can act as a good alterative in conjunction of new technological methods.

\title{
Keywords
}

\author{
Indigenous Knowledge, Runoff Harvesting, Recharge, Bandsar, Assessment, Iran
}

\section{Introduction}

Generally, more than $60 \%$ of Iran's landmass locates in the arid and semi-arid condition between 25 and 40 degrees of northern latitudes. Water, however, has not always been easy to come by in arid and semi-arid regions of the country, where rainfall events are very rare. Annual precipitation in Iran is $273 \mathrm{~mm}$-less than one-third of the world's mean annual precipitation [1] [2]. The most acute problem of water supply in Iran is the severe arid regions of the central and southeastern part, which receive $100 \mathrm{~mm}$ rainfall per year. In this region, soil moisture is generally limited and crop growth is stressed by drought during the growing season, resulting in decreased and unsustainable crop yields. However, similar to other arid regions, ancient Iranian settlers innovated some practical techniques for supplying water in order to reduce the effects of such harsh condition. In fact, such dire limits in water resources have brought about a general culture of hard work and innovation among nomadic and settled peoples of Iran to innovate and to use especial techniques and knowledge for supplying water which are recently called indigenous knowledge.

Qanat, Khooshab, Bandsar and Degar are the most famous indigenous techniques in water resources management in Iran. Unfortunately this oral indigenous knowledge which is inherited from the ancestors has been dramatically being forgotten.

There are several reports about traditional use of runoff in areas where the rain is not sufficient for crop farming. Flood spreading systems and flood irrigation have also been practiced in Iran for many years. In the western Rajestan, India, specific technology packages on rainwater management and runoff harvesting (such as: Nudi, Tanka, Khadin, Anicut) were developed to recharge ground water [3].

Flood irrigation is reported from North America, Kenya, the former Soviet Union, occupied Palestine, Australia, Afghanistan, Pakistan, Yemen, Tunisia, Burkina Faso and India [4]. In North America, Indian tribes have used simple methods of floodwater farming. They have use runoff from sandstone to water alluvial soils in Arizona. In pastoral community of Kenya with annual rainfall of less than $200 \mathrm{~mm}$, small patches of sorghum are grown using floodwater. Kovda (1961) reported the use of natural runoff in arid areas of the former USSR called Kair farming whose name is given to cropping on flood terraces (Evidences of flood farming can be found in different parts of Sudan, Morocco, Syria, Jordan and many other countries with similar climatic condition) [3] [4]. The object of this article is to introduce two major runoff harvesting techniques, Bandsar and Khooshab in central part of Iran.

\section{Traditional Water Management Systems}

About 2500 years ago, Persians living in present-day Iran invented a number of methods for exploiting, conserving, and storing surface and groundwater. In fact, natural dire limits in water resources have brought about a general culture of hard work and innovation among nomadic and settled peoples of Iran to innovate and to use especial techniques and knowledge for supplying water which are recently called indigenous knowledge. Different methods have been used for flood farming throughout the country with different names; among them are Bandsar, Khooshab and Degar. A runoff harvesting system may have four components, including an area of runoff generation, a system to pass on water for storage, storage tank to deliver water to the point of use or area for infiltration. In following parts of the paper Bandsar and Khooshab will be introduced and evaluated.

\subsection{Bandsar}

Bandsar is consisted of a basin surrounded by levees along the contour line and dry rivers and is generally constructed on the piedmont plain and alluvial fans. This basin, in fact, is a plot or a field for farming and is irri- 
gated by flood waters of upland dry land rivers (Figure 1). Generally the following parts could be distinguished in a Bandsar:

1) A shallow water drainage;

2) A small diversion rock-filled dam made of river sediment called diversion dam;

3) Contour levees (border);

4) Some parallel subsidiary walls (weir) for balancing water spreading;

5) A waterway for the overflow of water.

This traditional technique can be observed in east and northeast of Iran. Although the structure of Bandsar is very simple, it has many benefits such as increasing soil moisture, crop production, groundwater recharge, soil protection and preventing water loss to (in/of) playas (Kavir) and saline lakes. The watering of Bandsar is done by two following methods:

a) Conveyance of overland flow from impervious surrounding lands which have small elevation difference by a channel to Bandsar;

b) Conversion of runoff or floods from seasonal rivers to the field with a channel diverted from the river.

Because of the instability of levees there is a little information about exact history and dating of Bandsar. Moreover, due to flash flood in arid and semi arid and sedimentation it is necessary to spend time and expenditure to maintane and thus the ancient Bandsars are too scarce (Anonymous, 1983). The water trapped in the Bandsar can be used during dry seasons or it can infiltrate into deeper soil layers and increase moisture of downward lands. Mostly wheat and barley are cultivated in this land. Deposition of fine sediment particles (silt and clay) on the Bandsar basin cause fertility of soils and could be used as the adding fertile materials to sandy soils. The depth of water trapped in a Bandsar varies from 50 to $125 \mathrm{~cm}$. It is gradually depleted through seepage and evaporation, and is disappeared during the time, leaving the surface soil moist and fit for sowing. In these systems no fertilizer and irrigation is needed. In addition, the outlet waterway with a simple weir controls the depth of flooding water to prevent over toping of levees made of river sediment. Bandsar covers different areas between $100 \mathrm{~m}^{2}$ in valleys and 30 ha in gentle slope lands of piedmont [5] [6]. Generally, in alluvial fans, the land situated between two streams is suited for constructing Bandsar. After each flood, the new sedimentation causes that the surface of Bandsar shows a bright tone on the aerial photos and satellite images (Figure 2).

Most of Bandsars are located in the central and southern parts of Khorasan province in areas where annual precipitation is less than $200 \mathrm{~mm}$ [5] [6].

Based on common custom and local agreements, two methods are established among rural society to determine the priority of watering:

1) Upstream agreement: Based on this agreement the irrigation right in each flood event belongs to the farmer whose field (Bandsar) is located near the river at the upper point. After full irrigation of upstream Bandsar, the farmer gives the permission of irrigation to the next farmer whose field is located in the lower part of the stream. In the next flood event the irrigation right belongs to the first farmer again. In other words, the upstream farmer has the right to use water in all flood events.
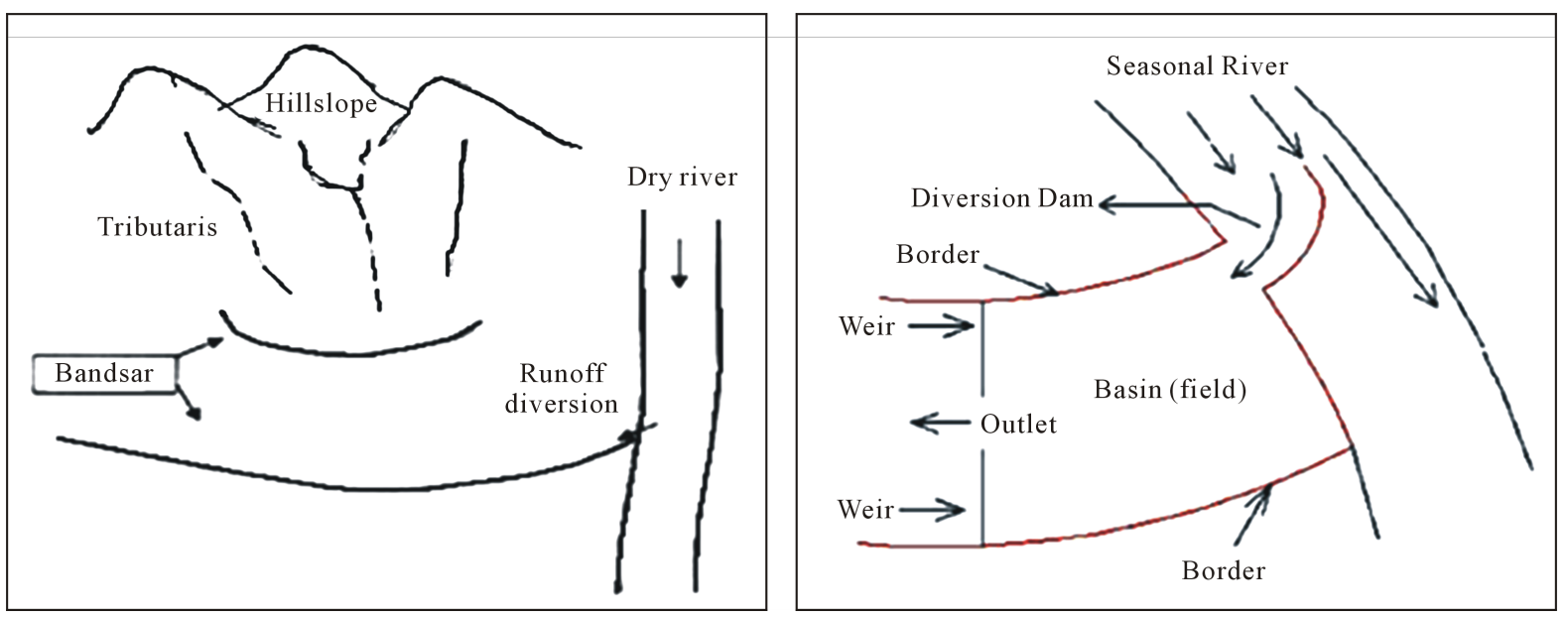

Figure 1. Schematic plan of a Bandsar. It is practiced where the piedmonts and mountainous catchments occur in proximity. 
2) Weekly cycle agreement: based on this agreement each day of week is contributed randomly to a farmer. Depending on the day of flood occurrence, the prior farmer to use water is determined. The next farmers are determined based on previously randomized schedule.

According to the physiography of land and source of runoff, Bandsar could be classified into three groups [5] [6]. Bandsar impounded by dry rivers and located on the alluvial fans, pediment Bandsar charged by overland flow of hilslope area, and Bandsar which is harvesting the upland tributaries runoff.

\subsubsection{Alluvial Fan Bandsar}

This type is constructed on the alluvial fans where flood flows originated from upland mountainous regions are spreading through the drainage pattern of fans (Figure 3). Land situated between two streams is suitable for constructing Bandsar.

Normally this type is similar to flood farms on the contour line which are irrigated by the seasonal flood. The upstream catchment area is not very large to generate big floods and destroy the Bandsar construction. They were mainly used for controlling flood and deposition of sediment in order to recharge ground water of down stream area. Distribution of them is concentrated in central, north eastern and eastern parts of Iran (e.g.: Sabzevar, Birjand, Qaen, Ferdos, Nehbandan) with annual average temperature and precipitation of $14^{\circ} \mathrm{C}-20^{\circ} \mathrm{C}$ and

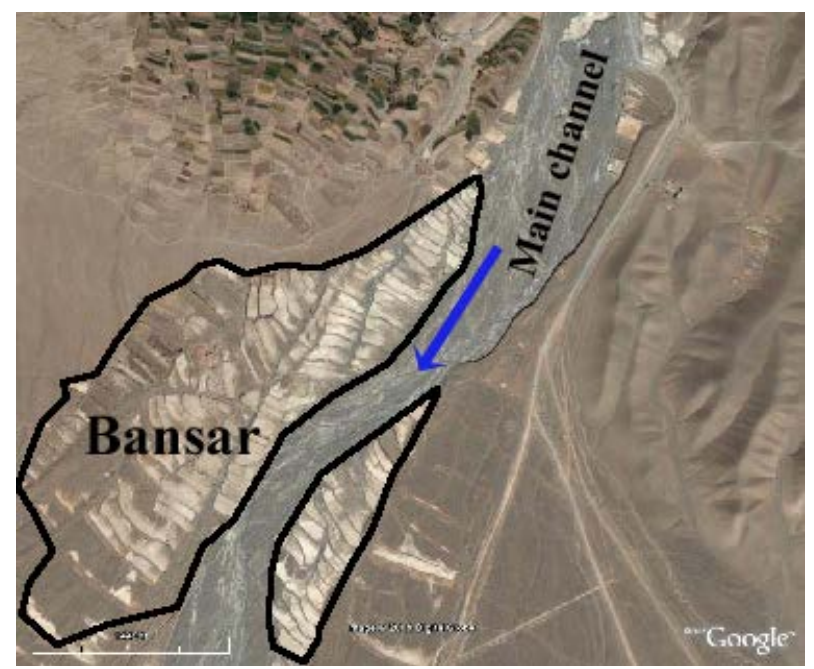

Figure 2. Satellite image (from Earth Google) of an alluvial fan Bandsar in Birjand. Sedimentation has resulted a bright tone of image.

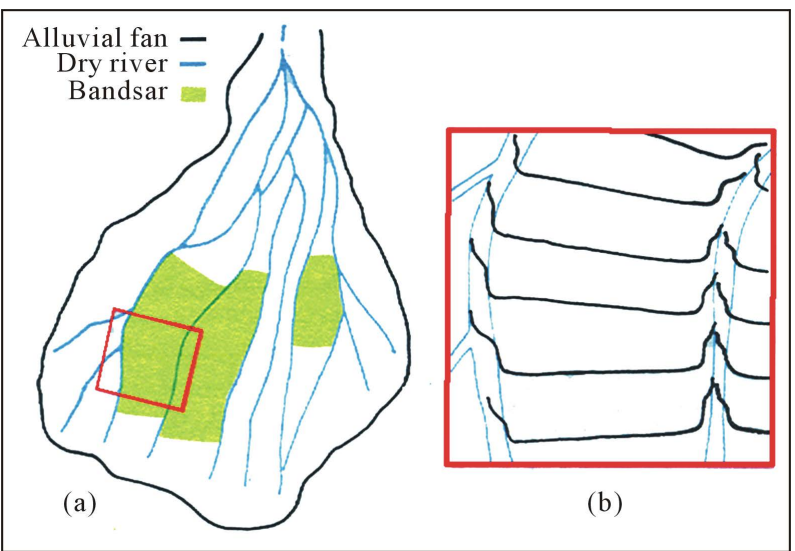

Figure 3. (a) A schematic of Bandsar on an alluvial fan; (b) The enlarged diagram of Bandsar and the method of flood diversion from dry river [2]. 
100 - $200 \mathrm{~mm}$ respectively. The slope of land varies from $1.5 \%$ to $4.5 \%$ (average $2.5 \%$ ) and the climatic condition is cold dry [7].

\subsubsection{Piedmont Bandsar with Overland Flow}

These Bandsars are designed to be constructed in low slope and relative flat plain where the concentration of flood in the dry river is not available. Therefore, the rural people create the long earth embankments transverse to general slope of land, to conveyance the overland flow of the plain into the Bandsars' fields which are used to crop production. The main aims of this Bandsar are crop production and ground water recharge. Also this type is used/applied in regions under dry cold climatic condition with annual precipitation of $200 \mathrm{~mm}$.

\subsubsection{Bandsar Which Is Harvesting the Upland Tributaries Flow}

In area adjusted by the hilly lands, the generated runoff is trapped by a series of low elevated embankments along the wide section of channels. This kind has the smallest area among Bandsar and is mainly used for crop production such as orchard and shrubs. In some cases, for passing on the excess flood water a waterway is designed to convey over flow. They are developed mostly in cold semiarid area and sometimes the farmers increase the width of valley floor to increase the volume of storage.

\subsection{Khooshab}

Khooshab is the other indigenous water harvesting system developed in arid southeastern regions of Iran, Sistan Va Baluchistan. It is similar to a cross-dam constructed by combination of soil and stone materials across a small and wide channel bed of hill creek [8]. The best location for Khooshab is alluvial traces and flood plains or pediment. Similar to Bandsar, their functions consist of depositing sediment and flood water harvesting at the ephemeral rivers. These constructions are fully adopted to use the runoff-generated form Monson rainfall regime during summer and consequently, they act as an erosion and flood as well as desertification control, increasing productivity and ground water of rural areas.

Figure 4 has shown a longitude section of a Khooshab. As can be seen, the core of the dam is made of earth, supported by rocks on both downsides. A Stone pitching with a small spillway is provided at the downstream to protect it from scouring and destroying. In addition, a drainage outlet is designed at the lowest part of Khooshab downstream to drainage the gravity water and to induce creating suitable situations for plugging and agricultural practices. It has a basin to trap sediment and an outlet to allow excess water to flow to the next Khooshab system or to flow in the stream for downstream water uses. Water stored behind the dam infiltrates into the soil, which can be used for crop production.

Design, repair and construction as well as maintenance of Khooshab are managed by the labour work of family members and consequently do not need a particular social organization and financial support. However, the construction costs depend on the area of Khooshab, stoning and fill at the downstream. This simple system is very efficient for cultivating of wheat, maize, barely, millet and dates. But it is noticeable that annual rainfall, soil depth (Khooshab age) and chemical quality of runoff are the most effective factors on Khooshab production rate. Ban-e-Moghol Khooshab is the oldest one in Sarvan located in SE Iran [7]. According to the location and the material used to construct Khooshab, three groups of Khooshab are recognized: river bank, piedmont and mountainous Khooshab [4]. This traditional measure could be founded in regions which annual precipitation is less than $150 \mathrm{~mm}$, and its area is between 1 and 10 ha [9].

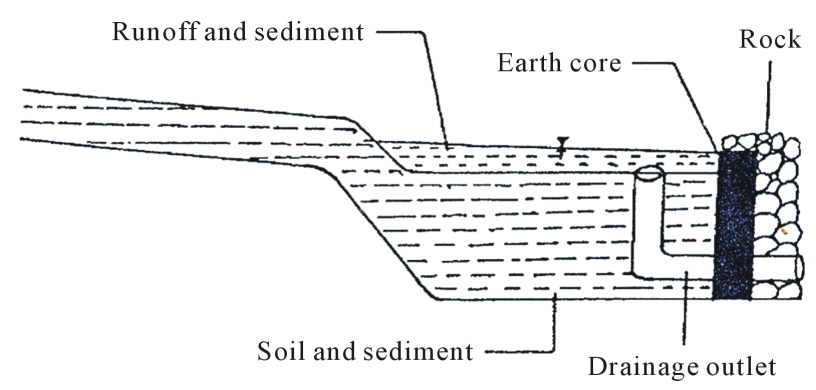

Figure 4. Longitudinal cross section of a Khooshab. 


\subsubsection{River Bank Khooshab}

Most of Khooshabs are in this group which is located by the river junctions and dry streams and is impounded by the flood water of them. All of Khooshab located by the Sarbaz and Mashkil rivers are river bank ones. Compared to other types, the slope and area of this Khooshab are small and large (up to $10 \mathrm{ha)}$ respectively. Mostly a series of them could be found as a compound system and can be used for cultivating at the first year of the construction. Moreover, because of the depositional rate of sediment after several years the height of dam should be increased [7]. The largest flood agriculture and horticulture fields are related to this type (Figure 5).

\subsubsection{Piedmont Khooshab}

Generally it is constructed in the piedmont plain and traces/terraces. This type has the largest field area and is impounded by a diverting channel from a big dry river. They could mostly be seen in Saravan, Iran-shahr and Nik-shahr of Baluchistan.

\subsubsection{Mountainous Khooshab}

On the channel bed of small dry rivers or in flat and relatively large area, runoff is stored by a low elevated earth dam. Generally rural people use the natural geomorphology (e.g.: hilly lands) to create such structures. Low elevated earth dam and high availability are the major characteristics of this type.

\section{Evaluation of Bandsar and Khooshab}

Similar to other indigenous knowledge, water harvesting methods have been invented by local society to satisfy/ meet their needs based on experienced knowledge and consequently, to have their own merits and limitations that determine where and when these methods could be used. These methods, in particular, have modified/developed geomorphology, socio-cultural and physical attributes to meet specific community needs in origin (al) area. However, for future planning it is necessary to have knowledge about the capability; as well as limitation of these structures described below.

In Bandsar system lack of sophisticated spill way to overflow and no compaction of levees' soil cause instability of them in flash floods and extreme events. Moreover, accumulation of salts could be observed due to evaporation and incoming sediments. Therefore shallow wells should be dug outside a Bandsar to utilize water in lower layers of the soil to increases seepage from the Bandsar and continuously the removal of salts. This water management system has many benefits such as increasing soil moisture, crop production, groundwater recharge, soil protection, and preventing water loss to saline lakes [8].

The accumulation of sediment inside a Bandsar causes a gradual rise in the level of the soil. Also, Sediments being deposited in Bandsar are usually fine grained which decreases the permeability of the soils over the time, but annual ploughing, cultivation of diverse plants as well as root penetration into the soil, all improve permeability and this is the main difference between a traditional multi-purpose flood spreading system and modern recharging systems [10].

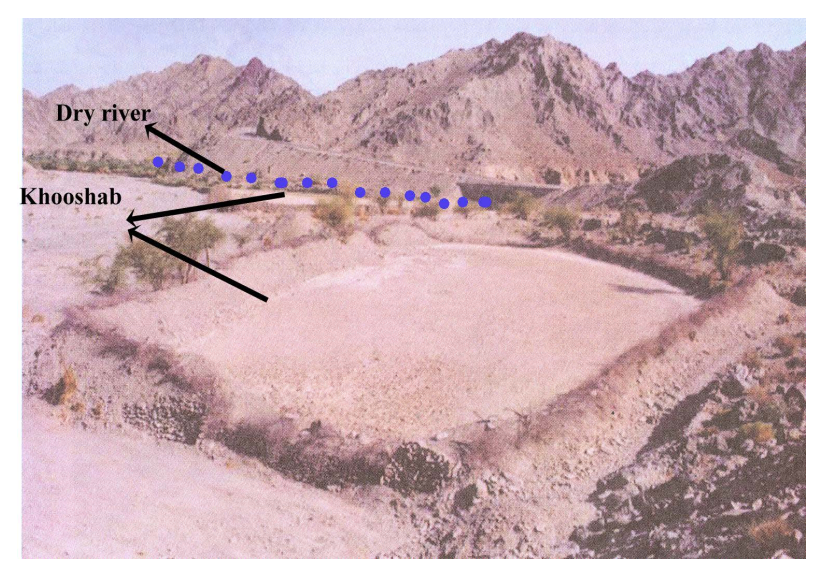

Figure 5. A series of river band Khooshab along Iran-shar to Chabahr road (Arabkhedri and Kamali, 2008). 
Trapped sediments behind the Bandsar are rich of organic matter (OM) which consists of animal manures and crop residues which can improve soil fertility. On the other hand, high porosity of these organic residues will improve the infiltration rate of heavy textured soils accumulated behind them. The main crops cultivated in this system are wheat and barley in rotation with melon and water melon. The other crops are cumin, sunflower and peas which can produce acceptable yields.

The results of Ashouri (2000) research for evaluating the effects of Bandsar on soil properties indicated that clay, silt, OM, Nitrogen, K and P increased in Bandsar's soil. In this regard, OM and P showed a remarkable increase, 17 and 3 times respectively [11]. He implied that deposited sediment in Bandsar could be used as a fertilizer for improving other area in arid regions.

Rahi et al. compared the traditional and new modern water harvesting methods in southwestern Iran and resulted that the ratio of benefit to cost (B/C) for Bandsar varies between 1.5 and 2.5 [12]. They have also stated that compared to modern techniques (e.g. check dam, terracing) simplicity in design and implementation of traditional measures in combination to maintenance costing of them, cause more preferable and public acceptance among rural community.

Based on Filekesh in the normal water year, the crop production (wheat or barley) in one hectare of Bandsar is about two tones, which in internal market is equal to 3,500,000 Rials (350 USD) [9]. However, due to some common expenses, the net income is about 200 - 300 USD.

Based on preliminary research, 1500 Khooshabs are recognized in Sistan Va Baluchistan of Iran. The productivity of different crops is stated in Table 1.

With acceptance of average area of 5 ha and wheat cultivation, the total income of Khooshabs is equal to US $\$ 4,850,000$. The results of other research conducted by Tavasoli to evaluate Khooshab, reveal that in excellent Khooshab, which produces twice a year with one time impounding, is about US \$1500 per hectare and for ordinary ones is equal to US $\$ 500$ [7]. Also, other intangible benefits such as ground water recharge, soil conservation, erosion and flood control should be added to above income. Therefore, it has changed the whole socio-economic situations of the area including availability of water for agriculture, horticulture; increasing overall agricultural production and creation of rural employment. Improving moisture and surface water availability means that farmers are motivated to introduce more profitable agricultural crops [8].

In socio-economic aspect, the indigenous runoff harvesting methods, Khooshab and Bandsar, are easy to implement and maintain. When these structures are built, cost is shared by the community in the form of providing labor and raw material collected from the surroundings. This also serves multiple purposes to produce crops, fruits and many kinds of agricultural productions in addition to collecting and storing water in soil layers and aquifer. The surrounding environment is left undisturbed, so it could be used as nature-friendly water management system, which can develop and coexist with the community's demand for water. The social dimension of these systems is extremely important. Most domestic/native people live in small communities and depend closely on each other. It allows those living in a desert environment adjacent to a mountain watershed to create a large oasis in an otherwise stark environment.

Although the construction of traditional methods is simple, the maintenance and stability of them are relatively difficult. They consist of the construction of earthen embankment and deflectors across the land to divert the flow into the fields. But large spates usually destroy the bunds and reduce irrigation of the fields. Furthermore, the very high sediment content of spate water tends to fill the diversion canals, which have to be cleaned

Table 1. Productivity of different crops in Khooshabs of Sis$\tan$ Va Baluchistan.

\begin{tabular}{cc}
\hline Crop & Productivity (tone/ha) \\
wheat & 1.5 \\
Barely & 1.6 \\
Water melon & $5-6$ \\
Melon & $5-6$ \\
Date & $10-12$ \\
forage & $10-15$ \\
\hline
\end{tabular}


regularly. So, the bunds are relatively inexpensive to rebuild, the overall cost of seasonal maintenance and repair of the scheme is high. On the other hand, traditional methods require participation and sharing that contributes to maintaining and improving social harmony. However, with change in society and introducing new technology, water management methods are also undergoing changes and new challenges. Some traditional methods may not be practiced at all in future and some other may have to be reintroduced to ensure environmental and ecological balance that modern methods might have overlooked/supervised/predicted [8].

The United Nations and other executive organizations are encouraging the revitalization of traditional water harvesting in arid areas; because they feel that it is important for sustainable water utilization. In this regard, executive organizations and NGO's can participate in providing funds, to encourage local people to co-operate as voluntary labors in several stages of executive works, especially in non-agricultural seasons. It may be easy for executive organizations and NGO's to help project managers with planning, design, and implementation. Most of the necessary construction and plantation materials may be supplied with low transportation cost [8] [10].

\section{Conclusions}

About $60 \%$ of Iran is located in an arid or semi-arid climate. Water shortages and an inappropriate distribution of precipitation motivated Iranians to develop indigenous methods to meet their water demands about 2500 years ago. Khooshab or Bandsar have emerged as the most appropriate technology for runoff harvesting and flood irrigation in arid and semi-arid regions of eastern and southeastern regions of Iran. Bandsar technique can be observed in east and NE of Iran. It has many benefits such as increasing soil moisture, crop production, groundwater recharge, soil protection, and preventing water loss to playas (Kavir) and saline lakes. Based on physiography of land and source of runoff it can be classified into three groups.

Khooshab is the other indigenous water harvesting measure developed in arid southeastern regions of Iran, Sistan Va Baluchistan. It is similar to a cross-dam constructed by combination of soil and stone materials across a small and wide channel bed of hill creek. Design, construction and relief as well as the repair of Khooshab are managed by the labor work of a family's members and consequently do not need a particular social organization and financial support. However, the construction costs depend on area of Khooshab, stoning and fill at the downstream. Also, according to location and material used to construct Khooshab, three different types of Khooshab can be distinguished.

The main crops cultivated in these systems are wheat and barley in rotation with melon and water melon. The other crops are cumin, sunflower and peas which can produce acceptable yields. The benefit of runoff harvesting in traditional techniques depends on natural situation, soil attributes and runoff quality. The net income of Bandsar is about US $\$ 200$ - US $\$ 300$ while for Khooshab varies between US $\$ 500$ to US $\$ 1500$ per hectare.

The potential for these approaches are tremendous; and detailed analysis is necessary for understanding the effects of different methods on water resources in watersheds in hydrologic or socioeconomic issues. It is evident that traditional water management methods still exist in many countries and like other indigenous knowledge; they have their own merits and limitations that determine where and when these methods could be used. However, for future programming it is necessary to have knowledge about the capability of them and their limitation as well. Recently, new water harvesting techniques have been introduced and executed by government organizations in Iran. Therefore, some of the traditional methods are being given up in favor of modern alternatives. Although the construction of traditional methods is simple, the maintenance and stability of them are relatively difficult.

One of the common reasons for the failure of soil conservation projects in the developing countries is the lack of effective participation of the beneficiaries in decision making, planning and implementing. However, compared with modern techniques of soil and water conservation measures (e.g. check dam, terracing), the simplicity in design and implementation of traditional measures together with lower maintenance costs, have caused more acceptance of them among the rural community. It seems that by incorporating beneficial elements of both kinds into one, a water supply system can be developed that will be sustainable in a long term.

To achieve the incorporation of these methods into modern technologies and engineering practices, local people should be empowered to manage and maintain water management systems. It seems that by collaboration between community, government and NGOs in water sectors the comprehensive-regular program should be carefully planned for maintenance and appropriate funding of water resources projects suffering from lack of attention in their long-term existence. Finally the following suggestions could be effective for cooperation/inte- 
gration between modern and traditional techniques:

- Financial support by government loans with low interest rate;

- Synergies between local co-operative communities;

- Development of standards structures with more stability;

- Using economic optimization for structures designing;

- Conduct research to find out the plants with higher-value and adaptation in runoff harvesting techniques.

\section{References}

[1] Ahmadi, H., Nazari Samani, A. and Malekian, A. (2010) The Qanat: A Living History in Iran. In: Schneier-Madanes, G. and Marie-Françoise, C., Eds., Water in Arid and Semi Arid Zones, Springer, 125-138.

[2] Mahdavi, M. (2004) Applied Hydrology. Vol. 2, 5th Edition, University of Tehran Press, Tehran.

[3] Khan, M.A. and Faroda, A.S. (1997) Water Hurvesting for Sustainability in the Indian Arid Zone of Rajasthan. Proceedings of the 8th International Conference on Rainwater Catchment Systems, Teharn, 357-365.

[4] Ghoddousi, J. (1999) Introduction of Flood Spreading Methods and Its Application. The First Workshop of Flood Management and Application, $226 \mathrm{p}$.

[5] Arabkhedri, M. (1995) Bandsar, a Traditional Method for Flood Management in Khorasan. Pajouhesh \& Sazandegi, 26, 80-85.

[6] Arabkhedri, M. and Partovi, A. (1997) Bandsar: A Practice in Optimum Using of Water and Soil Resources in an Arid Region. Proceedings of the 8th International Rainwater Catchment Systems Conference, Tehran, 86-95.

[7] Arbkhedri, M. and Kamail, K. (2008) Traditional Techniques of Soil and Water Conservation in Iran. Soil Conservation and Watershed Management Research Center of Iran, Technical Report, 107 p.

[8] Ghanbarpour, M.R., Ahmadi, E. and Gholami, S. (2007) Evaluation of Different Traditional Water Management Systems in Semi-Arid Regions (Case Study from Iran). Proceeding Water Saving in Meditrranean Agriculture \& Future Reserch Needs, Valenzano, 133-139.

[9] Filekesh, E. (1993) A View on Traditional Flood Water Management Systems in Sabzevar. Proceedings of Optimal Utilization of Tehran Area Lands, Tehran, 12-24.

[10] Goodarzi, M. and Daghigh, Y. Floodwater Harvesting, a Key to Sustainable Development in Arid and Semi Arid Areas.

[11] Ashouri, A. (2000) Effects of Flood Harvesting on Chemical and Fertility Attributes of Soil in Bandsar. M.Sc. Thesis, University of Tehran, Iran.

[12] Rahi, Gh., Ghoddousi, J., Fakhri, F., Tosi, T. and Nazari Samani, A. (2007) Social and Economic Assessment of Traditional and Modern Soil and Water Conservation Measures in Bushehr Province. 4th National Conference on Science and Technology of Watershed Management in Iran, Karaj. 
Scientific Research Publishing (SCIRP) is one of the largest Open Access journal publishers. It is currently publishing more than 200 open access, online, peer-reviewed journals covering a wide range of academic disciplines. SCIRP serves the worldwide academic communities and contributes to the progress and application of science with its publication.

Other selected journals from SCIRP are listed as below. Submit your manuscript to us via either submit@scirp.org or Online Submission Portal.
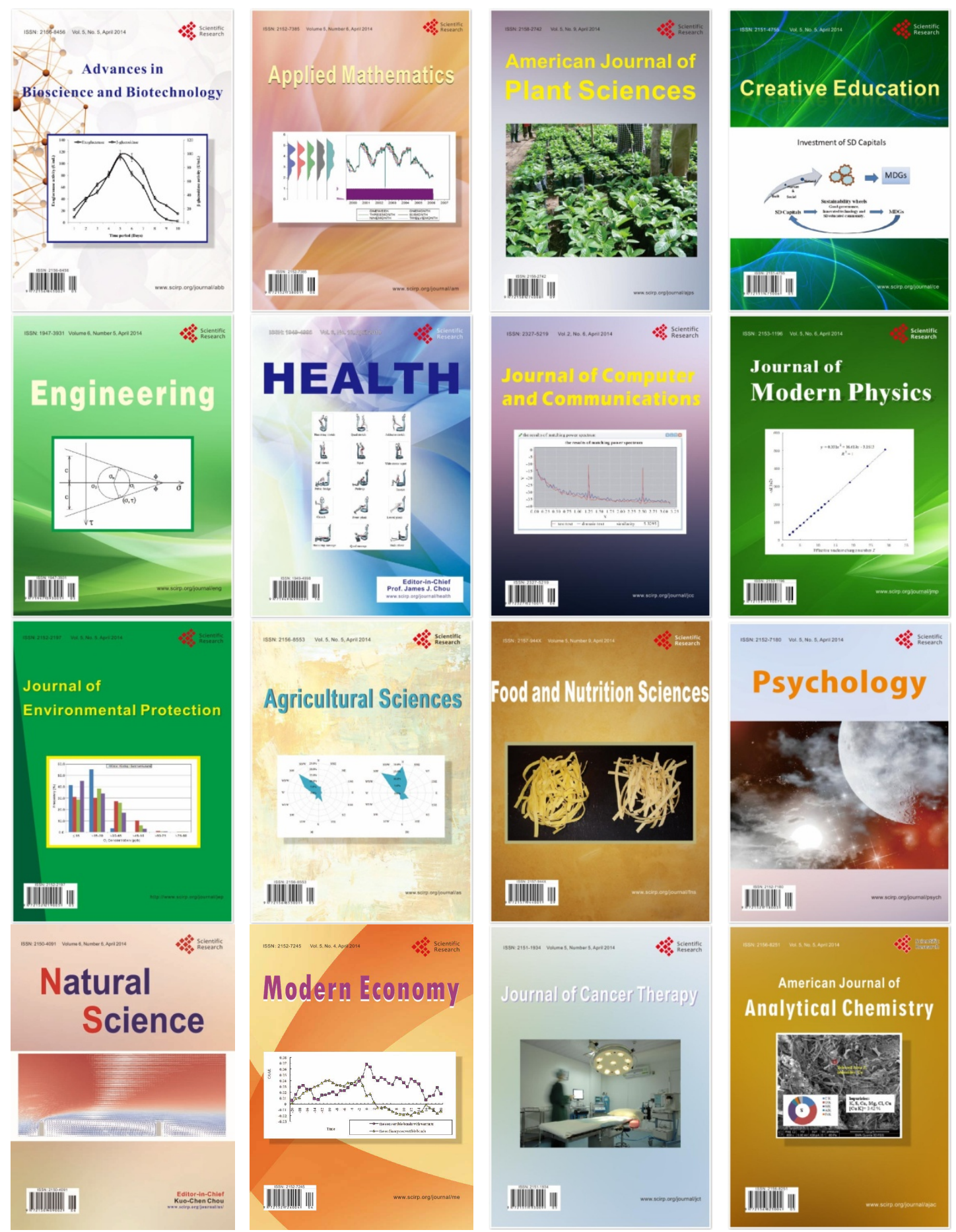